\title{
In Vitro Inhibition of Hepatitis C Virus by Antisense Oligonucleotides in PBMC Compared to Hepatoma Cells
}

\author{
Samar Samir Youssef, ${ }^{1}$ Ahmed Mohamed Fahmy, ${ }^{2,3}$ Moataza Hassan Omran, \\ Amr Saad Mohamed, ${ }^{4}$ Mohamed Ali El Desouki, ${ }^{4}$ and Mostafa K. El-Awady ${ }^{1}$ \\ ${ }^{1}$ Microbial Biotechnology Department, National Research Center, Cairo 12311, Egypt \\ ${ }^{2}$ Reproductive Health and Family Planning Department, National Research Center, Cairo, Egypt \\ ${ }^{3}$ INRS-Institut Armand Frappier, Laval, QC, Canada H7V $1 B 7$ \\ ${ }^{4}$ Chemistry Department, Faculty of Science, Cairo University, Cairo 12613, Egypt
}

Correspondence should be addressed to Samar Samir Youssef; youssefsamar1969@yahoo.com

Received 17 February 2014; Revised 7 April 2014; Accepted 10 April 2014; Published 1 June 2014

Academic Editor: Ramesh Prabhu

Copyright (C) 2014 Samar Samir Youssef et al. This is an open access article distributed under the Creative Commons Attribution License, which permits unrestricted use, distribution, and reproduction in any medium, provided the original work is properly cited.

\begin{abstract}
Aim. To assess the efficiency of phosphorothioate antisense oligodeoxynucleotide 1 (S-ODN1) on HCV translation inhibition in PBMC compared to hepatoma cells in vitro for the first time. Materials and Methods. The study included 34 treatment naive HCV patients. IRES domain III and IV sequence variations were tested in 45 clones from $9 \mathrm{HCV}$ patients. PBMC of HCV positive patients were subjected to S-ODN in vitro. Concomitantly HepG2 cells infected by the same patient's serum were also treated with S-ODN1 for 24 and 48 hours. Cellular RNA was tested for HCV plus and minus strands by reverse transcription polymerase chain reaction (RT-PCR). Results. Sequence variations were seen in HCV IRES domain III only while domain IV was conserved among all the tested patient's clones. S-ODN1 successfully inhibited HCV translation in HepG2 cells, while in PBMC inhibition was partial. Conclusion. HCV IRES domain IV is more conserved than domain IIId in genotype 4 HCV patients. S-ODN against HCV IRES domain IV was not efficient to inhibit HCV translation in PBMC under the study conditions. Further studies testing other S-ODN targeting other HCV IRES domains in PBMC should be done.
\end{abstract}

\section{Introduction}

Chronic hepatitis C virus (HCV) infection is a leading cause of chronic hepatitis, liver cirrhosis, and hepatocellular carcinoma [1-3]. The World Health Organization estimated that $3 \%$ of the world's population or approximately $130-170$ million people were chronically infected with HCV at the end of the 20th century, and 2.3-4.7 million new infections occur per year. Hepatitis $\mathrm{C}$ virus is also responsible for 300000 deaths annually [4]. HCV mainly is a hepatotropic virus with proven lymphotropism [5-7]. These cells represent an extrahepatic reservoir that can be implicated in virus recurrence and persistence $[8,9]$. Clearance of HCV RNA in peripheral blood mononuclear cell is a predictor of response to antiviral therapy in patients with chronic hepatitis C [10].

Six major genotypes of HCV have been identified worldwide [11]; HCV genotype 4 (G4) is common in the Middle
East and Egypt $[12,13]$ and has become increasingly prevalent in Southern European countries [14, 15]. Current standard therapy for G4 HCV infected patients is a 48 -week course of pegylated interferon (Peg-IFN) and ribavirin (RBV). The treatment goal is a sustained virologic response (SVR), defined as an undetectable HCV RNA load 6 months after treatment cessation. The SVR rate for G4 HCV infected patients after Peg-IFN/RBV treatment is approximately $60 \%$ [16]. Currently, novel compounds against the HCV-NS3 protease or the HCV-NS5B RNA-polymerase have entered clinical trials, showing high antiviral potency [17]. However, rapid HCV drug resistance to these agents has been shown to limit their efficacy, necessitating a combination with PEGIFN and ribavirin, which may cause a wide range of serious adverse reactions $[18,19]$. Consequently, antisense technologies are still needed in the future therapy for HCV. The $5^{\prime}$-end of the HCV genome contains a noncoding region $\left(5^{\prime} \mathrm{NCR}\right)$ of 
$341 \mathrm{nt}$, which is the most highly conserved region among all HCV strains [20]. It forms a stable secondary structure which contains an internal ribosome entry site (IRES) necessary for $\mathrm{HCV}$ translation/replication, representing an ideal target for antisense approaches.

Phosphorothioate modified ODN (S-ODN) is the first generation of antisense drugs entering clinical trials for the treatment of patients with chronic $\mathrm{HCV}$ infection which show acceptable properties for drug development [21].

Previous studies from our lab and others have shown the successful in vitro inhibition of HCV translation by antisense oligonucleotides directed towards the IRES [17, 22-26]. In our previous study and that of Alt et al. [22, 23], higher efficiency of S-ODN1 (directed towards IRES IId domain) compared to S-ODN2 (directed towards domain IRES IV domain) was reported but was not justified. In addition, SODN effect on HCV translation in $\mathrm{HCV}$ positive peripheral blood mononuclear cells (PBMCs) has not been investigated so far. The aim of this study was to evaluate the in vitro efficiency of S-ODN1 to inhibit HCV translation in patient's PBMC compared to hepatoma cells (HepG2), moreover, and to investigate sequence based reasons for higher efficiency of S-ODN1 versus S-ODN2.

\section{Materials and Methods}

2.1. Patients and Samples Processing. A total of 34 patients were included in the study; they were naive newly diagnosed HCV patients from the Medical Unit at the National Research Center, Cairo, Egypt. All patients were HCV antibody positive by third generation ELISA. Sera from $9 \mathrm{HCV}$ infected subjects were used in structural analysis of IRES domain III (loop IIId), while the rest twenty-five subjects were subjected to $\mathrm{HCV}$ detection in serum and PBMC in order to be further used for comparing S-ODN1 inhibition efficiency in HepG2 versus PBMC in vitro. The study was approved by the ethical committee of the National Research Center and a signed consent form was obtained from each patient. Patient's inclusion criteria were to be monoinfected by HCV detected by $\mathrm{HCV}$ antibodies (Ab) in serum and not suffering other disorders and not diabetic.

Ten $\mathrm{mL}$ blood was withdrawn from each patient, $7 \mathrm{~mL}$ on heparin and $3 \mathrm{~mL}$ without anticoagulant from which serum was collected by centrifugation. Ficoll centrifugation was used to isolate plasma and PBMC from blood. Plasma was collected and stored as aliquots in three Eppendorf tubes; PBMC was collected, washed with PBS five times, resuspended in RPMI 1640 media, and counted; then part of it $\left(2 \times 10^{6}\right.$ cells $)$ was used for detection of $\mathrm{HCV}$ and the rest was plated in 6 well plate $\left(1 \times 10^{6}\right.$ cells/well $)$ for testing SODN.

2.2. S-ODN Choice and Synthesis. According to previous reports including one from our lab [22, 23], efficient inhibition of viral replication in vitro was accomplished by two S-ODN, namely, S-ODN1 (nt 326-348) and S-ODN2 (nt 254-272), targeted towards HCV IRES domain IIId and IV, respectively. S-ODN1* has the same sequence of S-ODN1 with one mismatched nucleotide introduced (underlined nucleotide);

$$
\begin{aligned}
& \text { S-ODN1: (5'TGCTCATGGTGCACGGTCTACGA3') } \\
& \text { S-ODN1* : (5'TGCTCTTTGGTGCACGGTCTACGA3') }^{\prime} \text { S-ODN2: (5'GGCCTTTCGCGACCCAA3'). }
\end{aligned}
$$

Antisense phosphorothioate nucleotides were prepared and highly purified by Biognostik, Gesellschaft fur molekulare diagnostik, Gottingen, Germany.

2.3. Detection of HCV in Patient's Sera. Two-hundredmicroliter $(\mu \mathrm{L})$ serum from each patient was used for RNA extraction using QIAamp Viral RNA kit from QIAGEN (USA) according to the manufacture's manual. Two hundred ng of RNA was used to detect HCV by one step RT-PCR kit purchased from QIAGEN (USA) and used according to the manufacture's protocol. PCR products were visualized on $2 \%$ agarose gel.

2.4. HCV Genotyping in Serum and PBMC. Genotyping of $\mathrm{HCV}$ was done using nested PCR amplification of HCV core gene with genotype specific primers according to Ohno et al. [27]. Amplified PCR products were visualized on 2\% agarose gel.

2.5. Analysis of IRES Domain III Sequence from Local Samples. HCV domain III sequence was amplified by RT-PCR, then purified, and cloned as described in our previous study [28]. The ClustalW program was used (http://www.ch.embnet.org/ software/ClustalW.html) for alignment of the obtained sequences with genotype 4 prototype.

2.6. Analysis of IRES Domain IV Sequence from Local Samples. Published sequences of Egyptian HCV genotype 4 subjects with accession numbers AY838804, AY838805, AY838806, AY838807, Y838808, Y838809, AY838810, AY838811, AY838812, and AY838813 obtained from NCBI gene bank (http://www.ncbi.nlm.nih.gov/) and available at $\mathrm{HCV}$ database (http://www.hcv.lanl.gov/) were aligned and analyzed using ClastalW and biological sequence editor BioEdit programs for multiple sequence alignment and results were confirmed by the entropy plot generated by BioEdit program.

2.7. Detection of HCV Strands in Patient's PBMC. Total cellular RNA was extracted from counted uncultured patient's PBMC using Biozol reagent (Bioer, China) according to the manufacture's manual. HCV strands were detected by RTPCR as previously described [29]; briefly, $200 \mathrm{ng}$ of RNA was reverse transcribed to cDNA in $25 \mu \mathrm{L}$ reaction mixture containing $20 \mathrm{U}$ of AMV reverse transcriptase (Promega, Madison, WI, USA), $200 \mu \mathrm{M}$ of each dNTP, and 25 pmoles of either antisense primer (1CH: $5^{\prime}$-GGT GCA CGG TCT ACG AGA CCT $\left.-3^{\prime}\right)$ for plus strand or sense primer (2CH: $5^{\prime}$-AAC TAC TGT CTT CAC GCA GAA- ${ }^{\prime}$ ) for minus strand. The first round PCR was done in a total volume of $50 \mu \mathrm{L}$ using 50 pmoles from each primer $\left(2 \mathrm{CH}\right.$ and P2: $5^{\prime}$-TGC TCA TGG TGC ACG GTC TA-3 ${ }^{\prime}$ ). Twenty percent of the reaction was 


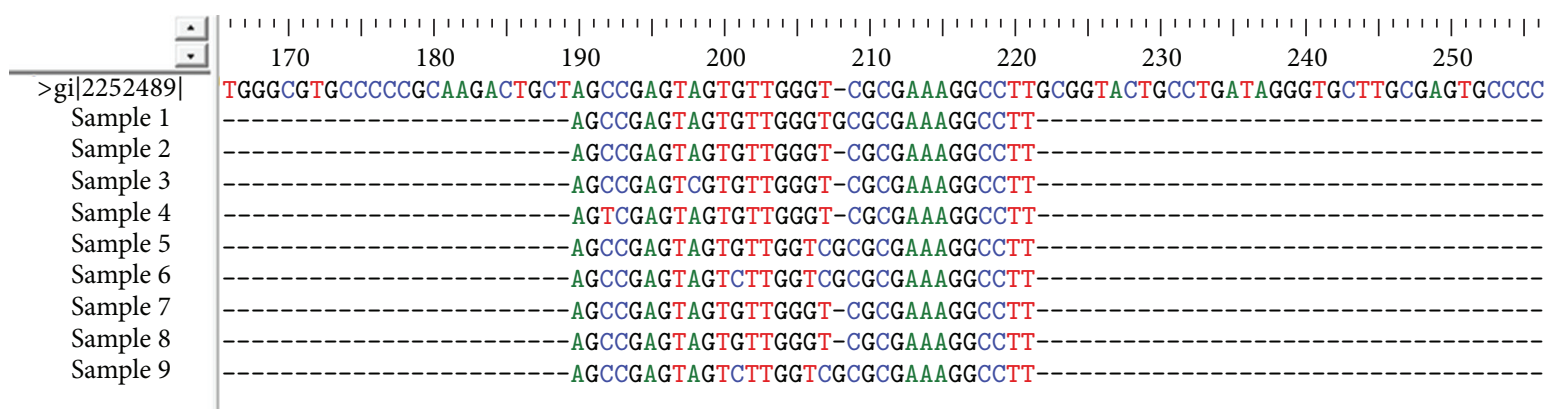

FIGURE 1: Multiple sequence alignment of AUG domain using ClustalW program. After sequencing, nine sequences comprising the AUG (34 nucleotides) were aligned using ClastalW program. The figure represents conservation of aligned sequences.

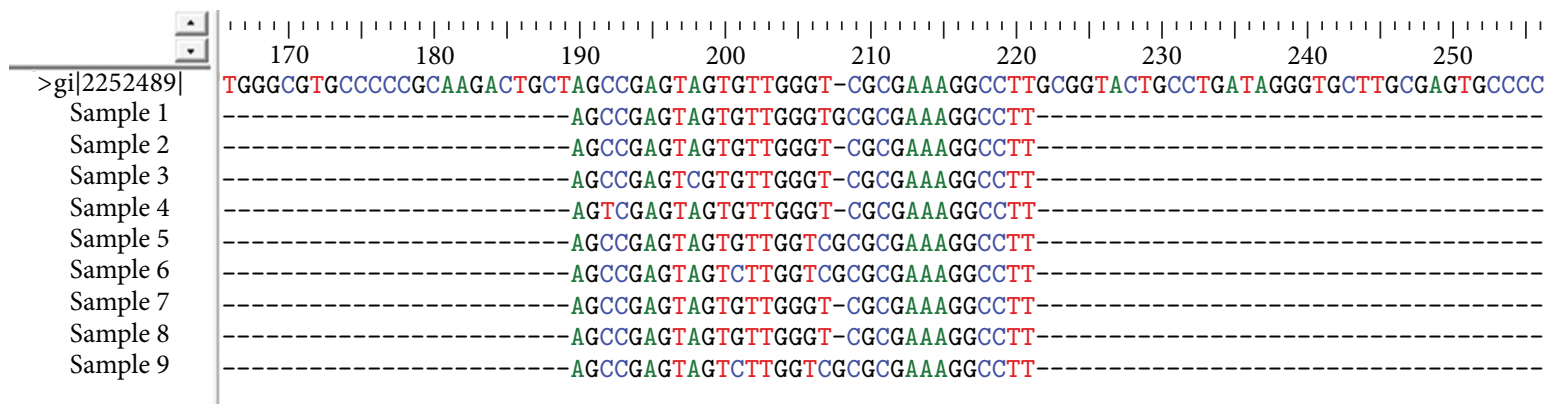

FIGURE 2: Multiple sequence alignment of loop IIId using ClustalW program. After sequencing, nine sequences comprising loop IIId were aligned using ClustalW program. Figure represents lower conservation with mutations C3-T3 in sample 4, A9-C9 for sample 3, G12-C12 for samples 6 and 9, G17-T17 for samples 5, 6, and 9, T18-C18 for samples 5, 6, and 9, and G19 insertion for samples 1, 5, 6, and 9.

used for a second amplification round with the internal pair of primers (D1: $5^{\prime}$-CGC AGA AAG CGT CTA GCC AT- $3^{\prime}$ and D2: $5^{\prime}$-ACT CGG CTA GCA GTC TCG CG-3'). Cycling conditions on the thermal cycler were the same as the first round. Products of PCR were analyzed on $2 \%$ agarose gel electrophoresis and photographed.

2.8. Testing of S-ODN Inhibitory Effect in Different Cell Types. Patients proved to be HCV positive in both serum and PBMC were included in this step. For each patient, $500 \mu \mathrm{L}$ serum was used for infected cultured HepG2 cells as previously described [22]; then cells were treated with $1 \mu \mathrm{M}$ SODN1 and $\mathrm{SODN1}^{*}$ (4 wells for each treatment) for $72 \mathrm{hr}$; control cells were kept without SODN. Concomitantly, PBMCs were separated by ficoll, washed 5 times with PBS, then resuspended in RPMI 1640 supplemented with $10 \%$ FCS, plated on a 6well plate at a concentration of $2 \times 10^{6} / \mathrm{mL}$, and cultured at $37^{\circ} \mathrm{C}, 5 \% \mathrm{CO} 2$ in absence or presence of $1 \mu \mathrm{M}$ SODN1 and $\mathrm{SODN1}^{*}$ (4 wells for each treatment) for $72 \mathrm{hr}$. Cells were harvested, washed 5 times with PBS, and subjected to total cellular RNA extraction. Total RNA extracted from cultured HepG2 cells and from PBMC was reverse transcribed and amplified using same assay described above and previously described to detect HCV plus and minus strand [29].

\section{Results}

3.1. HCV Genotyping in Serum and PBMC. Results of HCV genotyping in sera of all patients showed that all were genotype 4 . Similarly, genotype 4 was the only genotype detected from genotyping of $\mathrm{HCV}$ from PBMC positive patients included.

\subsection{HCV IRES Domain III and IV Sequence Conservation.} To assess IRES sequence conservation across HCV isolates, nucleotide sequences of 45 clones from $9 \mathrm{HCV}$ subjects were determined (and the most frequent sequence for the clones that belongs to each subject was selected) and the sequences that constitute the target domains for S-ODN1 and S-ODN2 were aligned using multiple sequence alignment programs ClustalW. Results revealed sequence conservation (Figure 1) at the region containing the AUG start codon (34 nucleotides), which was selected as target for S-ODN1, while stem loop IIId sequence, which was selected as a target for SODN2, was found to be relatively variable through multiple sequence alignment by ClustalW program (Figure 2).

3.3. Detection of HCV RNA in Patient's Serum and PBMC. All the 25 patients were HCV RNA positive in serum but only 10 out of them showed detectable HCV RNA in PBMC. Among them six patients showed detectable plus and minus HCV RNA strands while the rest 4 patients showed the presence of HCV plus strand only.

3.4. In Vitro Inhibition of HCV Replication Using S-ODN1 in Both Infected HepG2 Cell Line and PBMC. In the current 
TABLE 1: In vitro effect of SODN1 on HCV RNA in PBMC.

\begin{tabular}{|c|c|c|c|c|c|c|}
\hline \multirow{3}{*}{ Patient number } & \multicolumn{2}{|c|}{ Control } & \multicolumn{4}{|c|}{ PBMC } \\
\hline & \multirow[b]{2}{*}{ +ve strand } & \multirow[b]{2}{*}{-ve strand } & \multicolumn{2}{|c|}{$24 \mathrm{hr}$} & \multicolumn{2}{|c|}{$48 \mathrm{hr}$} \\
\hline & & & +ve strand & -ve strand & +ve strand & -ve strand \\
\hline 1 & +ve & - ve & +ve & -ve & +ve & - ve \\
\hline 2 & $+\mathrm{ve}$ & $+v e$ & +ve & +ve & +ve & $-\mathbf{v e}$ \\
\hline 3 & +ve & - ve & +ve & -ve & +ve & - ve \\
\hline 4 & +ve & +ve & +ve & +ve & +ve & +ve \\
\hline 5 & +ve & $+v e$ & +ve & - ve & +ve & +ve \\
\hline 6 & $+v e$ & +ve & $-\mathbf{v e}$ & +ve & +ve & +ve \\
\hline 7 & +ve & +ve & +ve & +ve & +ve & +ve \\
\hline 8 & +ve & - ve & +ve & $-\mathrm{ve}$ & +ve & - ve \\
\hline 9 & +ve & +ve & +ve & +ve & +ve & +ve \\
\hline 10 & +ve & $+v$ & +ve & +ve & +ve & - ve \\
\hline
\end{tabular}

study inhibition of HCV was defined as elimination of preexisting viral strand/s. Results showed that supplementation of the culture with S-ODN1 succeeds to inhibit HCV RNA strand/s in serum infected HepG2 cells after 24 hours at $1 \mu \mathrm{M}$ concentration and its effect was extended till 48 hours in all tested cases except one, while in PBMC S-ODN1 was considered to fail in inhibition of preexisting $\mathrm{HCV}$ RNA strand/s (Figure 3) after 24 and even after 48 hours in all patients tested, although partial inhibition of $\mathrm{HCV}$ manifested by loss of HCV minus strand in 2 patients after $48 \mathrm{hr}$ and in one patient after $24 \mathrm{hr}$ (Table 1) and loss of HCV plus strand in one patient after $24 \mathrm{hr}$ (Table 1). Complete viral inhibition was not detected in any of them.

\subsection{Effect of Variation of S-ODN1 Sequence on HCV Inhibition} in Different Cell Types. After testing S-ODN1 efficiency in different cell types. Effect of S-ODN1 sequence conservation on its inhibitory effect of HCV replication results is shown in Figure 4; one nucleotide mismatch in S-ODN 1 did not show effect on inhibition efficiency of the antisense oligonucleotide; furthermore, both S-ODN1 and its one nucleotide mismatched derivative were able to inhibit replication in HepG2 cells while both failed to inhibit replication in PBMC.

\section{Discussion}

Several groups including our laboratory have identified antisense oligonucleotides that inhibit HCV RNA and polyprotein synthesis both in vitro, cell culture, and in mouse models $[17,22,23,26,30-34]$.

Our laboratory previously used S-ODN structures designed against two phylogenetically conserved regions, the region comprising the AUG start codon (S-ODN1) and stem loop IIId (S-ODN2) [22]. The sequence data from local isolates revealed conservation at specific motifs related to proper folding and efficient translation, that is, IIId GGG (nucleotide 266-268) and AUG start codon (nucleotide 340-342), respectively. These data offered an advantage for antisense drugs as a therapeutic option for most known genotypes of HCV. One important and unjustified finding

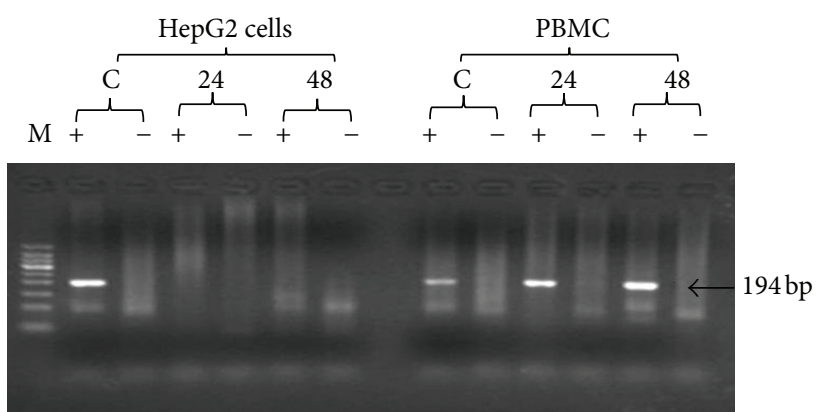

FIGURE 3: Agarose gel electrophoresis HCV nested PCR products in two different types of cells treated with S-ODN1. HCV infected HepG2 cells and PBMC were treated with SODN1 for 24 and 48 hours. Lane M: 50 bp DNA ladder. For HepG2 cells, lanes C (+, -): untreated HCV infected HepG2 cells cultured for $48 \mathrm{~h}$ amplified plus and minus strands, respectively, as a positive control, lanes $24 \mathrm{~h}(+,-)$ : plus and minus strands PCR products, respectively, for HCV infected HepG2 cells treated with S-ODN1 for $24 \mathrm{~h}$, and lanes $48 \mathrm{~h}(+,-)$ : plus and minus strands PCR products, respectively, for HCV infected HepG2 cells treated with S-ODN1 for $48 \mathrm{~h}$. For PBMC, lanes $\mathrm{C}(+,-)$ : plus and minus strands PCR products, respectively, for untreated $\mathrm{HCV}$ infected PBMC cultured for $48 \mathrm{~h}$ as a positive control, lanes $24 \mathrm{~h}(+,-)$ : plus strand and minus strands PCR products, respectively, for HCV infected PBMC treated with SODN1 for $24 \mathrm{~h}$, and lanes $48 \mathrm{~h}(+,-)$ : plus strand and minus strands PCR products, respectively, for HCV infected PBMC treated with SODN1 for $48 \mathrm{~h}$.

in this study is that S-ODN1 has relatively more inhibitory potency than S-ODN2, a finding that was supported earlier [23]. On the other hand, ISIS pharmaceuticals achieved a progression in transfer of the in vitro results to in vivo trials studies in a phase I clinical trial of ISIS14803 product in patients with chronic hepatitis $C$ infection who had previously not responded to therapy or were unsuitable candidates for standard therapies. ISIS study was designed to evaluate the safety and tolerability of four ISIS 14803 doses given by two routes of administration although the study was not focused on detecting significant changes in antiviral response rates between cohorts. In general ISIS 


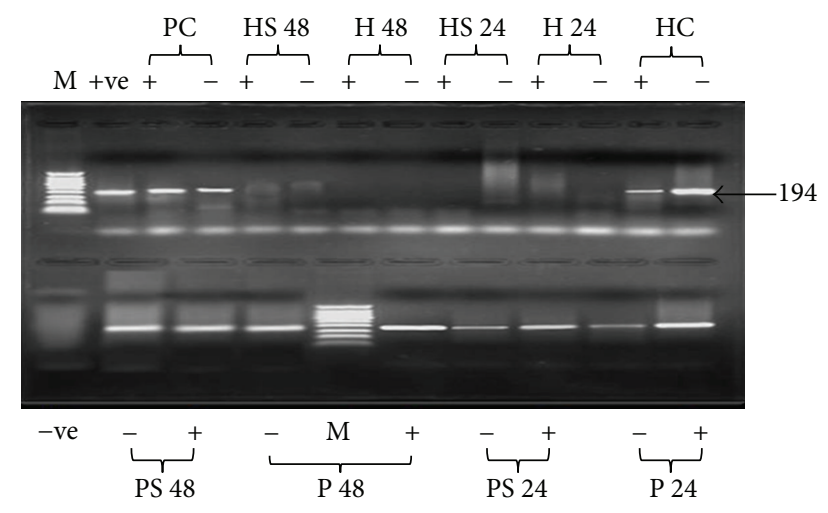

FIGURE 4: Agarose gel electrophoresis of HCV nested PCR products in two different types of cells treated with S-ODN1 and its derivative. HCV infected HepG2 cells and PBMC were treated with S-ODN1 for 24 and 48 hours. Lanes HC $(+,-)$ : untreated HCV infected HepG2 cells cultured for $48 \mathrm{~h}$ amplified plus and minus strands, respectively, and lanes $\mathrm{H} 24(+,-)$ : plus and minus strands PCR products, respectively, for $\mathrm{HCV}$ infected HepG2 cells treated with S-ODN1 for $24 \mathrm{~h}$, lanes HS $24(+,-)$ : plus and minus strands PCR products, respectively, for $\mathrm{HCV}$ infected HepG2 cells treated with SODN1 derivative for $24 \mathrm{~h}$, lanes $\mathrm{H} 48(+,-)$ : plus and minus strands PCR products, respectively, for HCV infected HepG2 cells treated with S-ODN1 for $48 \mathrm{~h}$, lanes HS $48(+,-)$ : plus and minus strands PCR products, respectively, for HCV infected HepG2 cells treated with S-ODN1 derivative for $48 \mathrm{~h}$, lanes PC $(+,-)$ : untreated HCV infected PBMC cultured for $48 \mathrm{~h}$ amplified plus and minus strands, respectively, +ve: positive PCR control, and lanes P $24(+,-)$ : plus and minus strands PCR products, respectively, for HCV infected PBMC treated with S-ODN1 for $24 \mathrm{~h}$, lanes PS $24(+,-)$ : plus and minus strands PCR products, respectively, for HCV infected PBMC treated with S-ODN1 derivative for $24 \mathrm{~h}$, lanes P $48(+,-)$ : plus and minus strands PCR products, respectively, for HCV infected PBMC treated with S-ODN1 for $48 \mathrm{~h}$, lanes PS $48(+,-)$ : plus and minus strands PCR products, respectively, for HCV infected PBMC treated with S-ODN1 derivative for $48 \mathrm{~h},-v e$ : is negative PCR control.

safety study was accompanied by ALT flares in a subgroup of patients. Transient plasma HCV RNA reductions greater than fluctuations generally seen in untreated patients were observed in 3 of 28 ISIS 14803-treated patients [21].

In the present study IRES domain III specifically the segment starting from nucleotide 141 to 279 derived from 9 different naïve randomly selected Egyptian patients exclusively infected with genotype 4 was amplified. Cloning of domain III and sequencing of 5 clones in each patient allowed the identification of the major variant (identical sequence in 4 clones or more) in each patient so that noise was reduced during extrapolation of the relationship between genomic variation and efficient selection of the most specific antisense nucleotide sequence.

Alignment of most frequent sequences belonging to each of the nine patients have shown that domain IV is highly conserved among all nine selected sequences specially the 34nucleotide stretch that comprises the AUG start codon; on the other hand loop III d showed a lower sequence conservation which may give a strong evidence on the higher efficiency of $\mathrm{S}-\mathrm{ODN} 1$ which is directed against domain IV over S-ODN2 which is directed against loop III $\mathrm{d}$ to arrest viral replication. Nonetheless, in our earlier study [22] alignment of $5^{\prime}$ UTR sequences was done for 17 clones from 5 genotype 4 patients only, and results showed nucleotide differences ranging from $3.5 \%$ to $5.3 \%$ when compared to isolates of type 4 used in this study; the two stem loop targets for S-ODN1 and S-ODN2 were conserved among all isolates analyzed except for a single mismatch in only one isolate.

The presence of HCV in extrahepatic sites may have profound implications in the pathogenesis of hepatitis $\mathrm{C}$ and treatment outcome. Evidence of $\mathrm{HCV}$ replication in granulocytes, monocytes, macrophages, dendritic cells, and B lymphocytes has been reported, although data were inconsistent. Further evidence for extrahepatic replication of $\mathrm{HCV}$ was provided by modeling of viral kinetics in patients during liver transplantation $[6,35]$.

Many studies have provided evidence on the existence of $\mathrm{HCV}$ replication in PBMC by the detection of $\mathrm{HCV}$ RNA minus strand the putative replication intermediate using strand-specific RT-PCR. Furthermore, PBMC was also considered a reservoir for HCV particles. Supporting evidence was given as fast viral decay in PBMC was associated with SVR [36]. Another study has shown the direct relation between SVR and absence of HCV RNA minus strand in PBMC [37].

In the current study naïve randomly selected local Egyptian patients exclusively infected with genotype 4 from which PBMCs were taken were selected and also the same patient serum was used to infect HepG2 cells in order to exclude viral heterogeneity effect and to narrow the focus on the efficiency of the treatment with S-ODN1 assuming that the serum and PBMC of the same patient will have the same variants.

Effect of mismatched oligonucleotides on HCV RNA levels was also studied by using S-ODN1 altered sequence after random introduction of a single nucleotide substitution which subsequently showed no effect on the potency of SODN1 to inhibit HCV replication, therefore, suggesting that S-ODN1 retains its high efficiency even after single base substitution.

Results of this study have shown that S-ODN1 was efficiently able to inhibit viral replication in infected HepG2 cells as indicated by the absence of plus and/or minus strands while, in contrast, it failed to inhibit viral replication in PBMC. These results suggested few explanations for the apparent cell tropism. The first explanation is the existence of distinct $\mathrm{HCV}$ variants in PBMC different from these present in hepatoma cells, a speculation based on results from previous studies which proved that tissue-specific mutations often occur in the HCV IRES, presumably because the cellular proteins that facilitate IRES function differ between cell types, driving the evolution of variants adapted for the local set of proteins [38]. The second explanation is that the concentration of S-ODN1 used was not sufficient to stop HCV translation in PBMC due to insufficient uptake of SODN by PBMC as no delivery system was used to enhance uptake of SODN by PBMC, consequently further studies in which a delivery system is used are recommended; while the third explanation may be that the translation initiation proteins in PBMC which physically interact in the translational complex 
for access to target may cause distinct secondary and tertiary structure changes in the RNA which differ from those in hepatoma cells and can prevent stringent oligonucleotide hybridization. However, this is one of several other viral and host factors that will determine translational efficiency and possibly resistance to treatment that need to be studied extensively in further studies.

In conclusion, S-ODN1 is efficient to inhibit HCV translation in hepatoma cells only and not in PBMC as extrahepatic translation site; consequently the use of antisense as antiviral treatment for $\mathrm{HCV}$ might necessitate its combination with PEGIFN/RBV in patients proved to harbor extrahepatic viral existence. The deficiency in the current study is the lack of data regarding the sequence of $\mathrm{HCV}$ in the studied patients. However, results of the current study urges the need for further studies on other HCV genotypes and with larger samples number to confirm results.

\section{Conflict of Interests}

The authors declare that there is no conflict of interests regarding the publication of this paper.

\section{References}

[1] G. M. Lauer and B. D. Walker, "Hepatitis C virus infection," The New England Journal of Medicine, vol. 345, no. 1, pp. 41-52, 2001.

[2] J. H. Hoofnagle, "Course and outcome of hepatitis C," Hepatology, vol. 36, no. 5, supplement 1, pp. S21-S29, 2002.

[3] M. J. Alter, "Epidemiology of hepatitis C virus infection," World Journal of Gastroenterology, vol. 13, no. 17, pp. 2436-2441, 2007.

[4] "Global surveillance and control of hepatitis C. Report of a WHO Consultation organized in collaboration with the viral hepatitis prevention board, Antwerp, Belgium," Journal of Viral Hepatitis, vol. 6, no. 1, pp. 35-47, 1999.

[5] D. Ducoulombier, A. Roque-Afonso, G. Di Liberto et al., "Frequent compartmentalization of hepatitis $C$ virus variants in circulating B cells and monocytes," Hepatology, vol. 39, no. 3, pp. 817-825, 2004.

[6] J. T. Blackard, N. Kemmer, and K. E. Sherman, "Extrahepatic replication of $\mathrm{HCV}$ : insights into clinical manifestations and biological consequences," Hepatology, vol. 44, no. 1, pp. 15-22, 2006.

[7] S. Pal, D. G. Sullivan, S. Kim et al., "Productive replication of hepatitis $\mathrm{C}$ virus in perihepatic lymph nodes in vivo: implications of HCV lymphotropism," Gastroenterology, vol. 130, no. 4, pp. 1107-1116, 2006.

[8] T. N. Q. Pham, S. A. MacParland, P. M. Mulrooney, H. Cooksley, N. V. Naoumov, and T. I. Michalak, "Hepatitis C virus persistence after spontaneous or treatment-induced resolution of hepatitis C," Journal of Virology, vol. 78, no. 11, pp. 5867-5874, 2004.

[9] M. Radkowski, J. F. Gallegos-Orozco, J. Jablonska et al., "Persistence of hepatitis $\mathrm{C}$ virus in patients successfully treated for chronic hepatitis C," Hepatology, vol. 41, no. 1, pp. 106-114, 2005.

[10] D. Z. Xu, Y. Xie, and Z. Q. Li, "Clearance of HCV RNA in peripheral blood mononuclear cell as a predictor of response to antiviral therapy in patients with chronic hepatitis C," Hepatobiliary and Pancreatic Diseases International, vol. 4, no. 4, pp. 550-553, 2005.
[11] P. Simmonds, "Genetic diversity and evolution of hepatitis C virus-15 years on," Journal of General Virology, vol. 85, no. 11, pp. 3173-3188, 2004.

[12] W. Sievert, I. Altraif, H. A. Razavi et al., "A systematic review of hepatitis C virus epidemiology in Asia, Australia and Egypt," Liver International, vol. 31, supplement 2, pp. 61-80, 2011.

[13] F. Abdel-Aziz, M. Habib, M. K. Mohamed et al., "Hepatitis $\mathrm{C}$ virus (HCV) infection in a community in the Nile Delta: population description and HCV prevalence," Hepatology, vol. 32, no. 1, pp. 111-115, 2000.

[14] S. Franco, C. Tural, B. Clotet, and M. A. Martínez, "Complete nucleotide sequence of genotype 4 hepatitis $\mathrm{C}$ viruses isolated from patients co-infected with human immunodeficiency virus type 1," Virus Research, vol. 123, no. 2, pp. 161-169, 2007.

[15] M. G. Ghany, D. R. Nelson, D. B. Strader, D. L. Thomas, and L. B. Seeff, "An update on treatment of genotype 1 chronic hepatitis C virus infection: 2011 practice guideline by the American association for the study of liver diseases," Hepatology, vol. 54, no. 4, pp. 1433-1444, 2011.

[16] S. M. Kamal and I. A. Nasser, "Hepatitis C genotype 4: what we know and what we don't yet know," Hepatology, vol. 47, no. 4, pp. 1371-1383, 2008.

[17] M. A. González-Carmona, A. Vogt, T. Heinicke et al., "Inhibition of hepatitis $\mathrm{C}$ virus gene expression by adenoviral vectors encoding antisense RNA in vitro and in vivo," Journal of Hepatology, vol. 55, no. 1, pp. 19-28, 2011.

[18] W. Aman, S. Mousa, G. Shiha, and S. A. Mousa, "Current status and future directions in the management of chronic hepatitis C," Virology Journal, vol. 9, article 57, 2012.

[19] M. L. Shiffman and R. Esteban, "Triple therapy for HCV genotype 1 infection: telaprevir or boceprevir?” Liver International, vol. 32, no. 1, pp. 54-60, 2012.

[20] J. Bukh, R. H. Purcell, and R. H. Miller, "Sequence analysis of the $5^{\prime}$ noncoding region of hepatitis $\mathrm{C}$ virus," Proceedings of the National Academy of Sciences of the United States of America, vol. 89, no. 11, pp. 4942-4946, 1992.

[21] J. G. McHutchison, K. Patel, P. Pockros et al., "A phase I trial of an antisense inhibitor of hepatitis $C$ virus (ISIS 14803), administered to chronic hepatitis C patients," Journal of Hepatology, vol. 44, no. 1, pp. 88-96, 2006.

[22] M. K. El-Awady, N. G. B. El-Din, W. T. El-Garf et al., "Antisense oligonucleotide inhibition of hepatitis C virus genotype 4 replication in HepG2 cells," Cancer Cell International, vol. 6, article 18, 2006.

[23] M. Alt, R. Renz, P. H. Hofschneider, G. Paumgartner, and W. H. Caselmann, "Specific inhibition of hepatitis C viral gene expression by antisense phosphorothioate oligodeoxynucleotides," Hepatology, vol. 22, no. 3, pp. 707-717, 1995.

[24] M. Gonzalez-Carmona, S. Schüssler, M. Serwe et al., "Hammerhead ribozymes with cleavage site specificity for $\mathrm{NUH}$ and $\mathrm{NCH}$ display significant anti-hepatitis $\mathrm{C}$ viral effect in vitro and in recombinant HepG2 and CCL13 cells," Journal of Hepatology, vol. 44, no. 6, pp. 1017-1025, 2006.

[25] V. Guerniou, R. Gillet, F. Berrée, B. Carboni, and B. Felden, "Targeted inhibition of the hepatitis $\mathrm{C}$ internal ribosomal entry site genomic RNA with oligonucleotide conjugates," Nucleic Acids Research, vol. 35, no. 20, pp. 6778-6787, 2007.

[26] M. A. González-Carmona, M. Quasdorff, A. Vogt et al., "Inhibition of hepatitis $\mathrm{C}$ virus RNA translation by antisense bile acid conjugated phosphorothioate modified oligodeoxynucleotides (ODN)," Antiviral Research, vol. 97, no. 1, pp. 49-59, 2013. 
[27] T. Ohno, M. Mizokami, R. Wu et al., "New hepatitis $\mathrm{C}$ virus (HCV) genotyping system that allows for identification of HCV genotypes 1a, 1b, 2a, 2b, 3a, 3b, 4, 5a, and 6a," Journal of Clinical Microbiology, vol. 35, no. 1, pp. 201-207, 1997.

[28] M. K. El-Awady, H. M. Azzazy, A. M. Fahmy et al., "Positional effect of mutations in $5^{\prime}$ UTR of hepatitis C virus $4 \mathrm{a}$ on patients' response to therapy," World Journal of Gastroenterology, vol. 15, no. 12, pp. 1480-1486, 2009.

[29] M. K. El-Awady, S. S. Youssef, M. H. Omran, A. A. Tabll, W. T. El-Garf, and A. M. Salem, "Soluble egg antigen of Schistosoma Haematobium induces HCV replication in PBMC from patients with chronic HCV infection," BMC Infectious Diseases, vol. 6, article 91, 2006.

[30] R. Hanecak, V. Brown-Driver, M. C. Fox et al., "Antisense oligonucleotide inhibition of hepatitis $\mathrm{C}$ virus gene expression in transformed hepatocytes," Journal of Virology, vol. 70, no. 8, pp. 5203-5212, 1996.

[31] M. Seki and Y. Honda, "Phosphorothioate antisense oligodeoxynucleotides capable of inhibiting hepatitis $\mathrm{C}$ virus gene expression: in vitro translation assay," Journal of Biochemistry, vol. 118, no. 6, pp. 1199-1204, 1995.

[32] O. Vidalin, M. E. Major, B. Rayner, J. L. Imbach, C. Trépo, and G. Inchauspé, "In vitro inhibition of hepatitis $C$ virus gene expression by chemically modified antisense oligodeoxynucleotides," Antimicrobial Agents and Chemotherapy, vol. 40, no. 10, pp. 2337-2344, 1996.

[33] T. Wakita and J. R. Wands, "Specific inhibition of hepatitis C virus expression by antisense oligodeoxynucleotides. In vitro model for selection of target sequence," Journal of Biological Chemistry, vol. 269, no. 19, pp. 14205-14210, 1994.

[34] H. Zhang, R. Hanecak, V. Brown-Driver et al., "Antisense oligonucleotide inhibition of hepatitis $\mathrm{C}$ virus $(\mathrm{HCV})$ gene expression in livers of mice infected with an $\mathrm{HCV}$-vaccinia virus recombinant," Antimicrobial Agents and Chemotherapy, vol. 43, no. 2, pp. 347-353, 1999.

[35] H. Dahari, A. Feliu, M. Garcia-Retortillo, X. Forns, and A. U. Neumann, "Second hepatitis C replication compartment indicated by viral dynamics during liver transplantation," Journal of Hepatology, vol. 42, no. 4, pp. 491-498, 2005.

[36] P. Pugnale, E. Herrmann, A. U. Neumann et al., "Hepatitis C viral kinetics in plasma and peripheral blood mononuclear cells during pegylated interferon- $\alpha 2 \mathrm{a} /$ ribavirin therapy," Journal of Hepatology, vol. 48, no. 6, pp. 932-938, 2008.

[37] G. Z. Gong, L. Y. Lai, Y. F. Jiang, Y. He, and X. S. Su, "HCV replication in PBMC and its influence on interferon therapy," World Journal of Gastroenterology, vol. 9, no. 2, pp. 291-294, 2003.

[38] S. L. Fishman and A. D. Branch, "The quasispecies nature and biological implications of the hepatitis C virus," Infection, Genetics and Evolution, vol. 9, no. 6, pp. 1158-1167, 2009. 


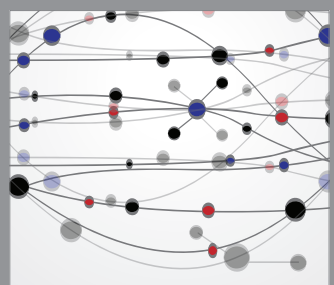

The Scientific World Journal
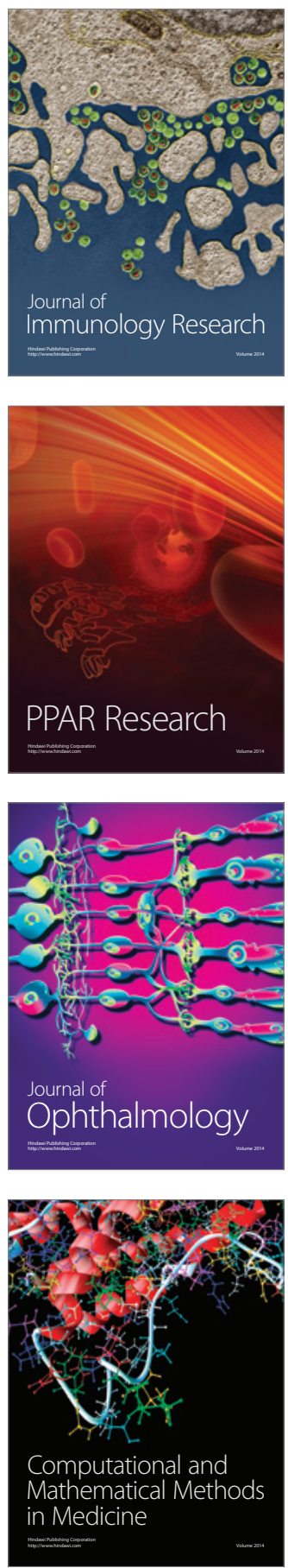

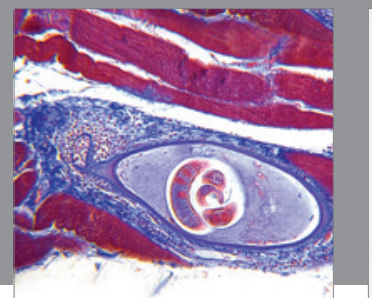

Gastroenterology

Research and Practice
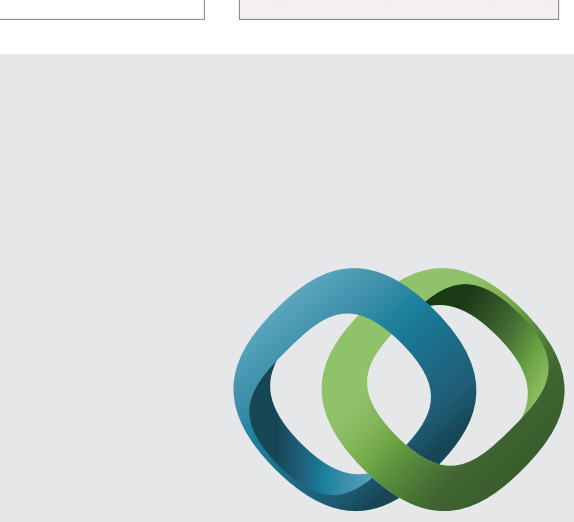

\section{Hindawi}

Submit your manuscripts at

http://www.hindawi.com
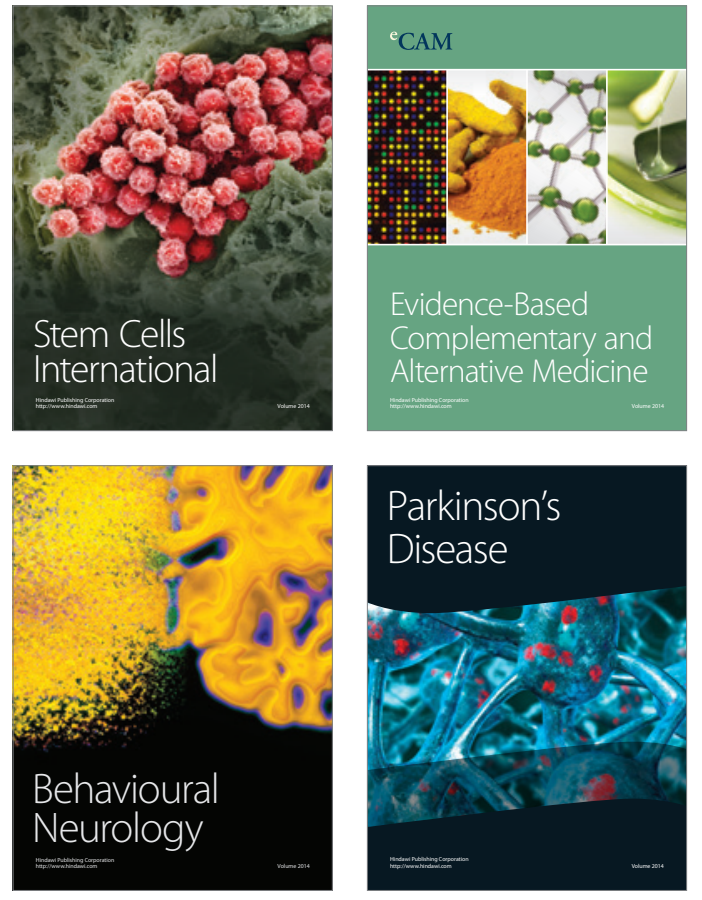
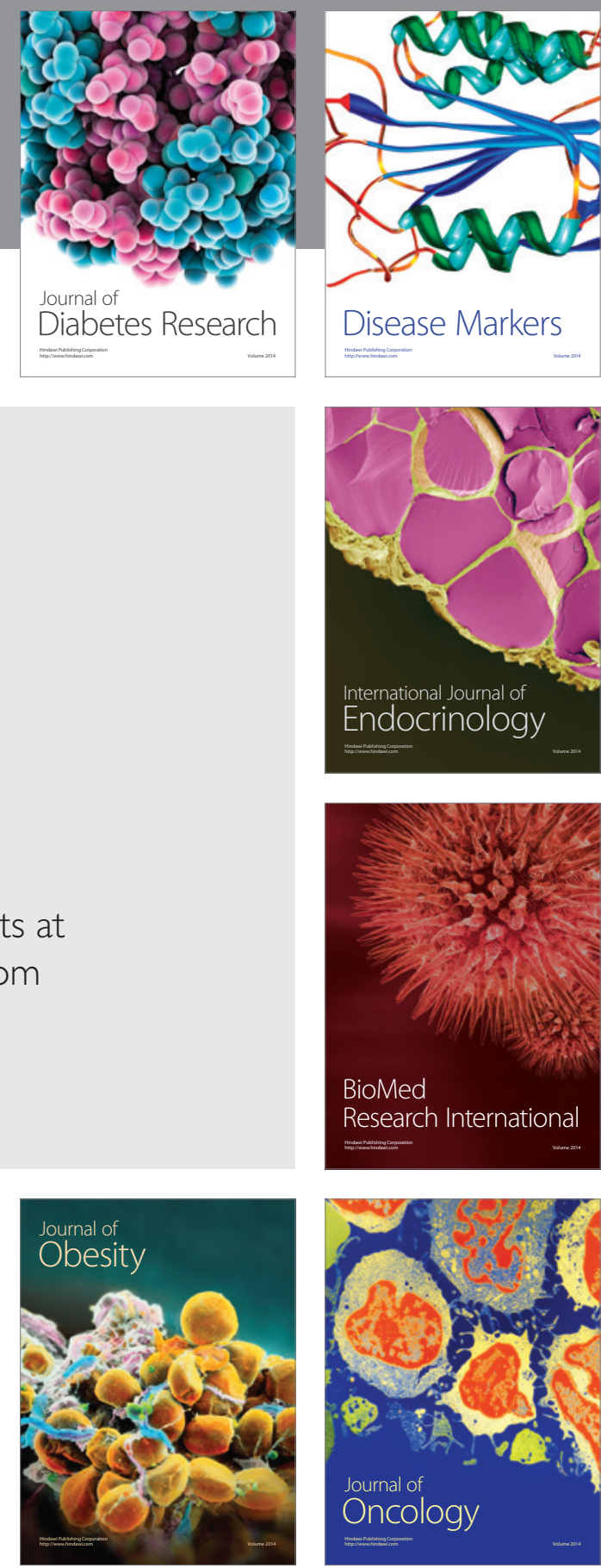

Disease Markers
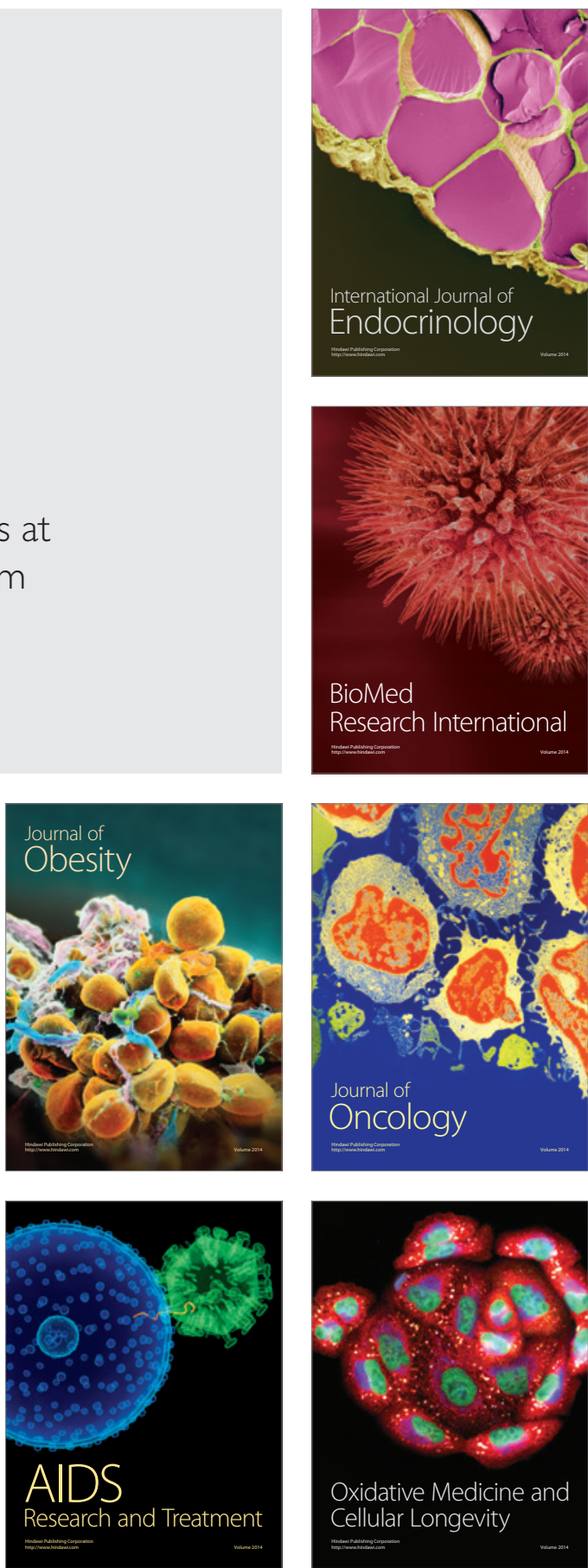